\title{
BRINQUEDO NO HOSPITAL
}

\author{
Edélia del Pilar Neira Huerta*
}

NEIRA HUERTA, E. del P. Brinquedo no hospital. Rev. Esc. Enf. USP, São Paulo, $24(3) 319-328$, dez. 1990.

No trabalho a autora apresenta algumas considerações a respeito da importância $e$ da utilização do brinquedo na assistência à criança hospitalizada.

UNITERMOS: Brinquedo. Criança hospitalizada.

\section{INTRODUÇÃO}

A assistência à criança hospitalizada deve incluir não apenas prestação de cuidados físicos, mas também, para ser efetiva, deve considerar e atender suas necessidades emocionais e sociais - devendo, portanto, incluir a utilização de técnicas adequadas de comunicação e relacionamento que permitam reconhecer e compreender essas necessidades.

Neste trabalho me propus a fazer uma revisão bibliográfica a fim de alinhavar algumas considerações a respeito da importância e da utilização do brinquedo na assistência à criança hospitalizada. Para esse propósito considerei necessário abordar três aspectos: primeiro, reações da criança à doença e hospitalização; a seguir, recursos para minimizar os efeitos da hospitalização na criança, e, finalmente, importância e utilização, particularmente pela enfermeira pediátrica, do brinquedo no hospital.

\section{Reações da Criança à Doença e Hospitalização}

Sem lugar a dúvidas, doença e hospitalização constituem uma crise na vida da criança. Diversos autores afirmam que a hospitalização representa uma experiência altamente estressante e traumática que afeta seu comportamento durante e após sua permanência no hospital.

Segundo KUNZMAN ${ }^{24}$, toda situação nova é ansiogênica para qualquer pessoa e sob quaisquer circunstâncias e, quando essa situação é doença, as pessoas procuram por rostos familiares e formas de conforto já conhecidas. A mesma autora comenta que nas crianças esta reação é

\footnotetext{
* Enfermeira. Mestre em Enfermagem Pediátrica. Professora Responsável pela disciplina Enfermagem Pediatrica da Faculdade de Enfermagem do Hospital Israelita Albert Einstein.
} 
muito mais marcante, pois, devido às suas características de desenvolvimento e às suas escassas experiências de vida, elas não têm a capacidade do adulto para tolerar mudanças e frustrações.

WHALEY \& WONG ${ }^{28}$ afirmam que quando são hospitalizadas, as crianças reagem principalmente à separação da mãe (família e ambiente do lar); à lesão corporal e à dor; ao ambiente hospitalar e à perda de controle que experimentam por sentirem que não mais podem prever o que vai lhes acontecer nesse ambiente desconhecido, como também por não poderem, devido à doença, continuar treinando as habilidades de desenvolvimento recentemente adquiridas.

ROBERTSON ${ }^{27}$, BOWLBY ${ }^{6}$, e PRUGH et alii ${ }^{24}$, apontam a separação da mãe como a principal causa das reações da criança à hospitalização. Eles afirmam que crianças entre as idades críticas de 0 a 5 anos passam por vários estágios de ansiedade.

ROBERTSON ${ }^{27}$ descreve três fases seqüênciais na resposta emocional da criança à separação da mãe: protesto, desespero e negação, considerando esta última como muito séria e indicativa de relacionamento mãe-filho severamente prejudicado.

BOWLBY ${ }^{\circ}$ é enfático ao afirmar que a privação parcial da mãe pode resultar em distúrbios nervosos e em uma personalidade instável, devido a que a criança, particularmente a criança pequena, não tem capacidade para lidar com as emoções e impulsos que a separação da mãe provoca nela.

RAMSEY ${ }^{25}$ afirma que a hospitalização de uma criança sempre dá origem a uma crise para toda a família. A criança em crise, como qualquer pessoa, não é mais capaz de resolver seus conflitos através de mecanismos já estabelecidos. Deste modo, a ansiedade aumenta ainda mais, levando a criança a se sentir confusa, desamparada e incapaz de encontrar soluções adequadas para seus problemas. Para a autora, isto decorre da hospitalização que separa a criança de seu meio familiar, no qual ela é capaz de prever os acontecimentos (rotiras familiares), colocando-a num mundo ameaçador, repleto de equipamentos desconhecidos e dominado por adultos estranhos. Deste modo a criança é obrigada a enfrentar situações para as quais não está preparada e então, a fím de encontrar respostas para atender sua falta de informação, ela fantasia. Também é comum que a hospitalização implique em procedimentos invasivos os quais ameaçam a imagem corporal da criança, levando-a a sentir-se vulnerável, insegura e dependente.

Segundo MASH \& DICKENS ${ }^{19}$, a criança hospitalizada sente-se ansiosa e infeliz em virtude, não só da doença, mas também da separação de seus pais, o que a levará a experimentar graus variados de estresse emocional. Ela pode acreditar que seus pais a estão deixando desamparada em um mundo de pessoas e arredores estranhos percebidos como hostis; pode sentir medo de estar sendo abandonada para sempre; experimentar raiva por estar sendo deixada entre estranhos e, perceber a hospitalização como uma punição, sentindo-se conseqüentemente culpada. 
KENNY ${ }^{13}$ descreve a seqüência de comportamentos exibidos pelas crianças como segue:

1. protesto $e$ medo: a criança está confusa e reage chorando ficando amedrontada e procurando insistente e intensamente por sua mãe;

2. apatia e fuga: devido ao alto nivel de ansiedade por não conhecer os diferentes aspectos da nova situação, a criança reage tornando-se apática e se isola. Isto, aos olhos de uma equipe despreparada é visto como sinal de um "bom paciente";

3. culpa: procurando compreender os motivos que a levaram à nova situação, a criança costuma percebê-la como sendo punição por algo errado que cometeu; e

4. tristeza: a criança experimenta auto-comiseração pelos procedimentos e experiências a que é submetida (até por antecipar essas experiências); pelo afastamento de seu ambiente normal; pela perda de sua energia habitual, preocupando-se constantemente com sua integridade física, especialmente com a possibilidade de mutilação.

Muitas crianças, particularmente aquelas separadas de suas mães durante o periodo de intermação, apresentam também dificuldades ao retornar ao ambiente familiar.

FREIBERG ${ }^{10}$ enumera os seguintes comportamentos novos da criança ao retornar ao seu lar após uma internação: demanda de maior atenção da mãe; tiques ou maneirismos; temores novos; choro quando a mãe se separa por curtos periodos; ciúmes de outro(s) membro(s) da familia; retraimento e acanhamento; insônia; pesadelos; comportamentos hostis para com os pais ;hábito de carregar ou segurar cobertores ou brinquedos; crises de birra e hiperatividade.

Para $\mathrm{BLOM}^{5}$, as reações emocionais das crianças à hospitalização são determinadas pelas fontes de tensão reais e inconscientes, pelo equilíbrio de forças internas da criança e de seus pais e pelo meio hospitalar que pode facilitar ou obstaculizar sua adaptação.

Segundo MACHADO \& MACHADO ${ }^{18}$, durante a hospitalização, a criança necessita, além de cuidados físicos, também de cuidados psicológicos, pois, devido ao trauma da separação da família, ao ambiente que lhe parece hostil e às próprias condições físicas evidentemente desfavoráveis, a hospitalização representa para ela uma tensão emocional dificilmente suportável se não for auxiliada e assistida pelo pessoal hospitalar com quem entra em contato.

\section{Recursas para Minimizar as Efeitos da Hospitalização na Criança}

Pelas considerações anteriores, perecebe-se a necessidade de buscar soluções que permitam minimizar os efeitos da hospitalização na criança, já que quando auxiliada a superar satisfatoriamente a crise da doença e hospitalização, se está favorecendo seu desenvolvimento e sua futura saúde mental. 
Numerosos autores, ROBERTSON ${ }^{27}$, PRUGH et alii. ${ }^{24}$, KENNY ${ }^{13}$, BARTON ${ }^{3}$, MACHADO \& MACHADO ${ }^{16}$, WHALEY \& WONG ${ }^{28}$ entre outros, afirmam que através de uma assistência hospitalar que considere, não apenas o cuidado físico e/ou o tratamento clínico, os efeitos da hospitalização podem ser bastante minimizados. Esses autores apontam vários recursos ou medidas que podem ser adotados na unidade pediátrica, a fim de promover uma assistência mais humanizada à criança. Entre esses recursos e medidas, eles citam:

- permitir e estimular a permanência contínua da mãe (pais) no hospital;

- permitir visitas irrestritas;

- favorecer e encorajar a participação dos pais nos cuidados prestados à criança

- evitar rodízios no pessoal que cuida da criança para que, desta maneira, ela possa estabelecer relacionamento de confiança com aqueles que cuidam dela;

- explicar às crianças - utilizando técnicas de comunicação adequadas - os motivos da hospitalização;

- preparar psicologicamente as crianças para todos os procedimentos a que serão submetidas;

- preparar adequadamente todo o "staff" que presta assistência às criariças no sentido de capacitá-lo a reconhecer e compreender suas reações e necessidades quando hospitalizadas;

- planejar e implementar assistência que atenda às necessidades físicas e psicológicas das crianças (e de sua família);

- adaptar, na medida do possivel, as dependências e utensilios da unidade de pediatria às necessidades de desenvolvimento das crianças (sala e recreação com prateleiras baixas, colchas e cortinas coloridas, uniformes coloridos, etc.); e

- UTILIZAR O BRINQUEDO como parte integrante de TODA a assistência à criança hospitalizada.

\section{Importância e Utilização do Brinquedo 10 Hospital}

Brinquedos e brincadeiras não são apenas para divertir e distrair a criança, sadia ou doente, e as pessoas que com ela brincam. Brincar é também uma das maneiras principais de descoberta de si mesmo, dos outros e do mundo que a cerca. Através da brincadeira, a criança aprende, exercita suas novas habilidades, percebe - encantada - coisas novas; digere medos e angústias, repete incessantemente o que gosta, explora investiga o que há ao seu redor.

BROOKS ${ }^{7}$ afirma que o brinquedo deve ser visto, não só como um meio de diversão e entretenimento, mas também como o trabalho da criança, a maneira pela qual ela aprende; é a forma da criança viver. 
Segundo NOBLE ${ }^{21}$, o brinquedo é o meio através do qual a criança se desenvolve emocional, social e intelectualmente e de forma natural.

ANDERSON ${ }^{1}$ esclarece que o mundo do brinquedo é o mundo que a criança conhece, bem como sua forma habitual de comunicação com 1 outras crianças e com os adultos também.

Nos modelos teóricos que explicam o desenvolvimento emocional e cognitivo, encontramos também fundamentos para a utilização do brinquedo no hospital.

ERIKSON ${ }^{\circ}$ considera que expressar seus conflitos através do brincar é a forma mais naturol de auto-terapia de que a criança dispōe. Segundo o autor, é possivel que o brincar desempenhe muitos outros papéis no desenvolvimento da criança, mas que sem lugar a dúvidas, a criança o utiliza para mitigar seus sofrimentos, frustrações e derrotas. O brincar é a forma infantil da capacidade humana para lidar com a experiência e dominar a realidade.

BETTELHEIM ${ }^{4}$ afirma ser crucial para o desenvolvimento da criança a liberdade de transformar um evento do qual ela é sujeito passivo num em que ela é o instigador e o controlador ativo. Segundo o autor a criança adquire dominio através da brincadeira e da fantasia. Inflingindo aos bonecos os processos que sofreu como sujeito passivo, a criança começa a entender que não precisa ser sempre a vítima desamparada, mas pode fazer a outros o que lhe foi feito. Desta forma, pela brincadeira, o sofrimento passivo torna-se um domínio ativo e os acontecimentos traumáticos em particular - como a hospitalização e todas suas facetas podem ser melhor dominados.

Para GUEESTS ${ }^{11}$, através do brinquedo, meio de expressão por excelência, a criança exerce um papel ativo, agindo sobre o real segundo suas fantasias e projetando no muncio externo seus receios e angústias com o objetivo de exercer domínio sobre eles. Assim, por meio de suas brincadeiras, a criança procura, primeiramente, dominar as experiências penosas que a realidade lhe impõe e, com o objetivo evidente de dominar sua angústia, a criança projeta no mundo exterior seus medos e suas apreensões.

Segundo PIAGET ${ }^{23}$, a criança pode reagir pelo jogo contra um medo ou realizar pelo jogo o que não se atreveria a fazer na realidade tornando-se este então catártico. No dizer do autor, na presença de situações penosas ou desagradáveis a criança pode apresentar um tipo de jogo simbólico caracterizado pelas combinações liquidantes em que a criança procura reviver a situação mediante transposições simbólicas.

Percebe-se desta forma, que onde há crianças não pode faltar brinquedos e brincadeiras - inclusive, e, ao meu ver, particularmente no ambiente hospitalar.

NOBLE ${ }^{21}$ opina que o brinquedo é de suma importância para a criança hospitalizada porque não apenas assegura a continuidade de seu 
desenvolvimento, como também ajuda a criança a encontrar alguma normalidade num ambiente estranho e ameaçador.

KUNZMAN 14 afirma ser o brinquedo uma fonte de recursas disponivel ao pessoal hospitalar para auxiliar a criança a superar a experiência de hospitalização pois: promove oportunidade da criança lidar com seus sentimentos, os quais não pode expressar facilmente em palavras; favorece algum tipo de atividade física; oferece oportunidade para aprendizado e crescimento; mostra à criança que sua necessidade de brincar é reconhecida e que, portanto, mesmo no meio hospitalar há amizade e consideração para com ela.

Scgundo CONN 8 , o brinquedo permite à criança expressar-se de uma maneira natural, uma vez que a comunicação verbal com cla é às vezes difícil e de pouco valor.

PETRILLO \& SANGER ${ }^{22}$ consideram o brinquedo de grande importância para a criança hospitalizada porque, além de proporcionar-lhe oportunidade de reorganizar sua vida, seus sentimentos e diminuir sua ansiecade, lhe permite que realize, em parte, aspectos normais de sua vida. Acrescentam as autoras que quando a criança carece de oportunidade para brincar, freqüentemente recorre a comportamentos destrutivos e agressivos. As mesmas autoras afirmam ainda que o brinquedo pode ser utilizado para ajudar as crianças a reconhecerem seus sentimentos, assimilarem uma nova situação, compreenderem o que se passa no hospital e esclarecer conceitos errôneos.

MACHADO ${ }^{15}$ aponta que uma importante função do brinquedo é a dramatização de papéis, de conflitos e catarse. Graças a essa catarse, além de possibilitar o diagnóstico de um conflito que a criança esteja vivenciando, o brinquedo tem tambérn função curativa pois atua como "válvula de escape" conduzindo assim à diminuição da ansiedade. MACHADO ${ }^{15}$ afirma ainda que esta função catártica é tão importante que constitui a base da psicoterapia infantil, a ludoterapia.

BARTON ${ }^{3}$ afirma que através da observação do brinquedo da criança, o observador habilidoso pode inferir significados que a criança é incapaz de verbalizar. A autora também opina que a presença de um adulto aceitador, que encoraje a criança a expressar seus sentimentos abertamente, é muitas vezes essencial.

PETRILLO \& SANGER ${ }^{22}$ ressaltam que, graças a seu contato de 24 horas com as crianças, $a$ equipe de enfermagem está em excelente posição para evitar que as crianças ocultem seus sentimentos durante períodos de tensão.

BARTON $^{3}$ afirma que o brinquedo é um instrumento efetivo de enfermagem que possibilita à enfermeira:

- estabelecer relacionamento com a criança;

- obter informações relativas aos conceitos da criança sobre sua doença e hospitalização, a fim de estabelecer objetivos para a assistência de enfermagem; 


\section{- comunicar à criança aceitação e informações;}

- preparar a criança para experiências novas e amedrontadoras;

- esclarecer conceitos errados a respeito da hospitalização e, inclusive, - conseguir modificações de comportamento da criança.

GREEN ${ }^{12}$ afirma que o brinquedo terapêutico, técnica de utilização do brinquedo fundamentada nas próprias funçōes do brinquedo e nos principios da ludoterapia, pode ser empregado por qualquer enfermeira, para qualquer criança hospitalizada, com o objetivo de permitir à enfermeira alguma compreensão das necessidades e sentimentos da criança. GREENN ${ }^{12}$ diz que durante a realização do brinquedo terapêutico são refletidas apenas as expressões verbais da criança e nunca suas atividades. A autora acrescenta ainda que as sessões de brinquedo terapêutico podem ser realizadas na sala de brinquedos ou de recreação da unidade pediátrica, na cama da criança ou em qualquer outra área conveniente e, sua duração é de 15 a 45 minutos.

Segundo BARTON ${ }^{3}$, o brinquedo terapêutico é também a utiilzação do brinquedo simulando situações hospitalares onde a criança receberá explicações dos procedimentos a que deverá ser submetida ou, descarregará a tensão após os procedimentos, visualizando as situações e manuseando os instrumentos ou suas imitações.

Em nosso meio, MORAES et alii. ${ }^{20}$, MARTINS ${ }^{17,}{ }^{18,}$ RIBEIRO ${ }^{26}$ e ANGELO $^{2}$ demonstram em seus trabalhos como conseguiram auxiliar crianças hospitalizadas utilizando o brinquedo terapêutico na assistência de enfermagem como um recurso para: estabelecer comunicação e relacionamento com a criança; conhecer seus sentimentos e preocupações; favorecer alívio de sua tensão e preparar a criança para procedimentos desagradáveis, inclusive cirurgias.

Como enfermeira e docente de enfermagem pediátrica acredito que as enfermeiras da área devam preocupar-se constantemente em procurar e implementar meios que auxiliem as crianças hospitalizadas a vivenciar da maneira menos traumática possível essa difícil experiência.

Pelas considerações apresentadas neste trabalho constata-se ser 0 brinquedo um excelente recurso para auxiliar à criança durante (e após) a experiência hospitalar, recurso este sobre o qual todas as enfermeiras que trabalham com crianças deveriam adquirir conhecimentos, particularmente a técnica do brinquedo terapêutico, e fazer dele uma parte importante da assistência que prestam, utilizando-o desde o momento da admissão da criança à unidade pediátrica até sua alta hospitalar.

NEIRA HUERTA, E. del P. Toy in hospital. Rev. Esc. Ent. USP, São Paulo, 24(3):319-328, Dec. 1990.

In this paper the author presents some considerations about the importance and the use of toy in thecare of the hospitalized child.

UNITERMS; Toy. Child hospitalized 


\section{REFERENCIAS BIBLIOGRAFTCAS}

1. ANDERSON, E.G. The child in hospital: play and emotional needs. Aust. Nurnses J., Melbourne, 7(11):54-7, June 1978.

2. ANGELO, M. Brinquedo: um caminho para a compreensão da criança hospitalizada. Rev. Esc. Innt. USP, São Paulo, 19(3) :213-23, dez. 1985.

3. BARTON, P.H. Nursing assessment and intervention through play. In: BERGERSEN, B.S. et alli. Current concepts in clinical nursing. Saint Louis, Mosby, 1969. p.203-7.

4. BETTELHEIM, B. Uma vida para seu filho: pais bons o bostanto ajudam seu filho a ser a pessea que ele deseja. Rio de Janetro, Campus, 1988. 32p.

5. BLOM, G.E. The reactions of hospitalized children to illness. Pediatrics, Evanston, 22(3): 590-600, Sept. 1958.

6. BOWLBY, J. Cuidados maternos e saúde mental. São Paulo, Marting Fontes, 1981. 225 p.

7. BROOKS, M.M. Why play in hospital? Nurs. Clin. North Am., Philadelphia, 5(3):431-41, Sept. 1970.

8. CONN, J.H. The child reveals himself through play. Ment. Hyq., New York, 23(1):49-69, Jan. 1939.

9. BRIKSON, E.H. Infancia e sociedade. Rio de Janeiro, Zahar, 1971. 404 p.

10. FREIBERG, $\mathbf{K}$. How parents react when their child is hospitalized. Am. J. Nurs., New York, 75(5):836-8, May 1975.

11. Geests, C. Malanie Klein. São Paulo, EdUSP, 1977.

12. GREEN, C.S. Understanding children needs through therapeutic play. Nursing, Springhouse, 4(10):31-2, Oct. 1974.

13. KENNY, T.J. The hospitalized child. Ped. Clin. North Am., Philadelphia, 22(3):583-93, Aug. 1975.

14. KUNZMAN, L. Some factors influencing a young child's mastery for hospitalization. Nurs. Clin. North Am., Philadelphla, 7(1):13-26, Mar. 1972.

15. MACHADO, D.V.M. O brinquedo e suas funções. An. Nestlé, São Paulo, (100):54-8, 1977.

16. \& MACHADO, E.M. Cuidados psicológicos à criança hospitalizada. Rev. Hosp. Clin., 11(4) :205-8, jul./ago. 1956.

17. MARTINS, D.M.R. Assistencia de enfermagem às crianças hospitalizadas quando enfrentam situaç̃es desagradáveis: parte I. Rev. Esc. Enf. USP, São Paulo, 13(2):157-69, ago. 1979.

18. - Assistencia de enfermagem às crianças hospitalizadas quando enfrentam situacões desagradáveis: parte II. Rev. Esc. Ent. USP, São Paulo, 13(3):287-99, dez. 1979.

19. MASH, J.B. \& DICKRiNS, M. Armstrong and Browder's nursing care of children. 'Philadelphia, Davis, 1973.

20. MORAES, E. et alli. Estudantes de enfermagem assistem crianças utilizando centrevista com brincadeirà. Hev. Esc. Enf. USP, São Paulo, 13(1):29-39, mar. 1979.

21. NOBLE, E.' Children in hospital: why play? Nurs. Times, London, 70(15):534-6, Apr. 1974.

22. PETRILLO, M. \& SANGER, S. Cuidado emocional del niño hospitalizado. México, Prensa Médica, 1975. $318 \mathrm{p}$.

23. PIAGET, J. A tormação do símbolo na criança: imitação, jogo, sonho, imagem o repré sentaģ̃o. Rio de Janeiro, Zohar, 1971. $370 \mathrm{p}$. 
24. PRUGF, D.F. et all. A study of the emotional reactions of chlldren and familles to hospitalization and Illness. Am. J. Orthopsychistry, New York, 23(1):70-106, Jan. 1963.

25. RAMSEY, N.L. Effects of hospitalization on the child and the family. In: SMITH, M.J. et alli. Child and family: concepts of nursing practice. New York, Mc. Graw Hill, 1982. Cap. 16. p. 317-41.

26. RIBEIRO, C.A. Sentindo o valor das experiencias slgnificativas para a aprendizagem: relato de duas situaçães vividas com crianças hospitalizadas. Bev. Hsc. Ent. USP, Såo Paulo, 17(3):179-203, dez. 1983.

27. ROBERTSON, J. Some responses of young children to the loss of maternal care. Nurs. Times, London, 49(16):382-6, Apr. 1953.

28. WHALEY, L.F. \& WONG, D.L. Enfermagem pediatrica: elementos essencials a inter-

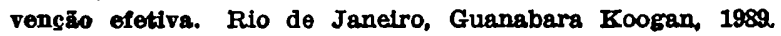

Recobldo em 17/10/89 